\title{
ALÉM DA MARGEM, “OS CANIBAIS" DE ÁLVARO DO CARVALHAL
}

Filipe Reblin ${ }^{1}$

RESUMO: Álvaro do Carvalhal é um autor português que está posto às margens do cânone literário, seja por questões acadêmicas ou pelo enquadramento que se faz de sua obra. O presente trabalho tem como proposta elaborar um diálogo que possa abordar aspectos referentes a essa questão e uma breve análise de seu conto "Os Canibais" publicado no livro Contos (2004).

Palavras-Chaves: Álvaro do Carvalhal, “Os Canibais”, Literatura Portuguesa.

\section{BEYOND THE EDGE, “OS CANIBAIS" OF ÁLVARO DO CARVALHAL}

ABSTRACT: Álvaro do Carvalhal is a Portuguese author standing in the fringe of literary canon, either by academics questions or by the way which his work is qualified. This paper aims to develop a dialogue in order to discuss this question and make a short analysis of his tale "Os Canibais" published in the book Contos (2004).

KEYWORDS: Álvaro do Carvalhal, “Os Canibais”, Portuguese Literature.

\footnotetext{
${ }^{1}$ Mestrando do Programa de Pós-Graduação em Letras da Universidade Federal do Paraná.
} 
Álvaro do Carvalhal é um escritor português que - apesar da efêmera passagem deixou uma pequena obra com marcas profundas de maturidade e, que merece, por nossa parte, um olhar atento e cuidadoso.

Nascido em Padrela, norte de Portugal, em 03 de Fevereiro de 1844, Álvaro teve uma vida extremamente curta, visto que morre aos 24 anos. Frequentou o Liceu de Braga e, em 1864, foi para a Faculdade de Direito da Universidade de Coimbra. Cresceu num meio familiar propício ao cultivo da arte literária, já que seu pai se dedicava à poesia, seu tio, Júlio do Carvalhal, foi colaborador de inúmeros jornais e do Almanaque de Lembranças, e era primo de Ifigénia do Carvalhal, que também publicou um conto em $A$ Chrysalida, jornal de literatura.

Sua primeira publicação ocorre em 1863, quando estreia como autor dramático, com "O castigo da vingança", peça em três atos com ambientação no Brasil e dividida da seguinte forma: $\mathrm{O}$ negro, A vingança e $\mathrm{O}$ castigo da vingança. Ao chegar a Coimbra, em 1864, começa a colaborar com a imprensa.

Quando estava no quarto ano da Faculdade de Direito, foi diagnosticado com aneurisma. Não acreditando no prognóstico médico, que lhe impedia de fazer certas coisas, como banhar-se e, sem perceber o agravamento da saúde, se dedicou à preparação do livro que conteria seus contos. O livro estava quase pronto quando, em 14 de Março de 1868, veio a falecer.

Há de se perceber que seus escritos, em grande ou pequena medida, refletem sua vida. Contendo, assim, traços autobiográficos. Quanto a isso, afirma-se:

Creio não haver dúvidas de que a criação da figura de J. Moreno se baseia amplamente em motivos autobiográficos, e nela encontramos não só a transfiguração da realidade vivida como igualmente os sonhos de glória social e política, velados sempre de ironia, de um jovem estudante... (MIRAGLIA, 2004, p.288)

Evidentemente, isto não diminui a força de sua obra ou desvanece a forma estilística por ele utilizada.

O livro Contos, postumamente apresentado por José Simões Dias - relevante autor na Literatura Portuguesa nos últimos anos do século XIX -, traz os contos produzidos pelo autor: “A Febre do Jogo", “J. Moreno", "Honra Antiga", “A Vestal!”, “O Punhal de 
Rosaura", "Os Canibais". O conto "Os Canibais" havia sido, primeiramente, publicado com o nome de "A Estátua Viva” na Revista Coimbra em Dezembro de 1865.

Não podemos deixar de mencionar que o autor se encontra à margem do cânone oitocentista, apesar de ser classificado, conforme o crítico português Luciano Cordeiro, no Livro de Crítica, como sendo parte da escola satânica, na qual também figuram autores mais conhecidos, como: Byron, Poe, Baudelaire (CORDEIRO, 1869, p. 289-291).

\section{A revolução fantástica, a presença do desconhecido no conhecido.}

A escrita portuguesa possui, desde muito cedo, a experiência do mistério e a presença de almas de outros mundos (ainda que esta característica não seja apenas da literatura lusitana). Percebemos isso quando nos deparamos com obras, tais como: Obras do Diabinho da Mão Furada, atribuída ao escritor e dramaturgo nascido no Brasil, António José da Silva, o Judeu, ou nos traços do insólito no teatro vicentino.

Um dos motivos para isso ocorrer, no período oitocentista, deve-se ao isolamento prolongado que Portugal vivenciou - fruto direto de uma grande censura que proibia a presença de traduções de obras estrangeiras, que pudessem de alguma forma se tornar objetos de subversão em terras lusitanas. Além, é claro, da presença de um movimento romântico tardio - se tivermos como parâmetro outros lugares da Europa, como França, Alemanha, Inglaterra -, que traz consigo: “[...] consequente precariedade na assimilação de alguns valores e conteúdos [...]" (CARNEIRO, 1992, p.18). A Arte era vista, segundo Carneiro (1992, p.18), não como uma demonstração estética, mas uma forma de rejeitar o passado e ser um instrumento de reforma e formação.

Mesmo tímida, a presença do fantástico português é visível. Nas palavras do escritor e ensaísta português, Sampaio Bruno:

A gente portuguesa, amorosa, contemplativa, sonhadora, com esse inesgotável fundo de quimera que lhe ficou da tradição religiosa, do ensino das visões místicas, do maravilhoso dos milagres e da alucinação do inferno, é notavelmente própria para produzir dentre si engenhos excêntricos, onde a imaginação sobreleve e se imponha ao simples bom senso, dando a realidade narrativa ao pesadelo, numa harmônica correspondência com o efeito da alma popular, que, na sua miragem coletiva do sebastianismo, procurou nos versejadores anônimos o estilo 
com que convinha fixar a sua fantasmagoria. (BRUNO, 1984, p.93) [grifo nosso] ${ }^{2}$

Tal panorama leva os leitores portugueses ao gosto por uma literatura com aspectos da escrita gótica que chegava, sobretudo, por parte de folhetins franceses, fazendo, assim, com que houvesse um crescimento de autores secundários, repetidores de fórmulas já gastas. Ou, nas palavras do escritor português Álvaro Manuel Machado (1986, p. 125), uma predominância por autores secundários em detrimento de autores principais.

Fora as traduções estrangeiras, publicadas largamente em jornais, as revistas (como exemplo: $O$ Mosaico, O Panorama) e até mesmo o teatro intervêm na divulgação deste tipo ficcional. Acerca desse ponto, Carneiro (1992, p.19) dirá que o frenesi e a mediocridade de autores secundários, hoje esquecidos, triunfam.

Alguns poucos escritores portugueses consagrados se aventuraram no uso do fantástico - apesar da relação que se fazia com a baixa qualidade, ligada ao fator da popularidade. Porém, nem o primeiro período do romantismo português, nem o segundo, deixaram de marginalizar o uso do fantástico (CARNEIRO, 1992, p.20). Alexandre Herculano, no entanto, parece ter preparado o terreno para o florescimento do sobrenatural, com a publicação em 1843 de "A Dama Pé-de-Cabra", na revista O Panorama.

A partir de 1865, o fantástico parece ter certo momento de efervescência em Portugal. O segundo período do romantismo português, numa ampliação do roman noir das primeiras décadas do século XIX, continuava a explorar os temas de terror, como $O$ esqueleto (1848), de Camilo Castelo Branco. Em 1864, Antero de Quental traduzia para o português um conto de Edgar Allan Poe e, nessa mesma época, Eça de Queirós faz publicações que apontam para a presença de um fantástico 'visionário', que encaminha para a presença de outros mundos. Com a publicação de O Mandarim (1880), Eça mantém viva essa tradição para além dos limites cronológicos de 1866/1867.

É neste contexto que jovens acadêmicos e poetas assumem um tom mais social, junto com um interesse pelo ceticismo romântico e pelo satanismo (de poetas como Poe, Baudelaire, Nerval, Heine, por exemplo).

Assim, é no meio de uma geração efervescente e com anseios (CARNEIRO, 1992, p. 28), que se pode inserir Álvaro do Carvalhal (mesmo com sua precoce morte) para

${ }^{2} \mathrm{~A}$ data de 1984 diz respeito ao texto que temos acesso. O original de "O conto fantástico" foi publicado em $A$ geração nova (os novelistas) em 1886. 
“reformar a humanidade!” (MIRAGLIA, 2004, p.284). Juntamente com jovens envolvidos com a Questão Coimbrã, ele desejava que a sociedade lusitana do seu tempo despertasse da sonolência e mediocridade que até então viviam - embora nem todos os contos fantásticos de Carvalhal cheguem a ser publicados integralmente nesse período. Hábil contista, Carvalhal era conhecido pelo desprezo aos eufemismos - com os quais normalmente se classificavam as coisas não ditas, o escândalo e o repugnante - pela ousadia temática (erotismo exacerbado, canibalismo), pelo interesse em demonstrar obsessões, anormalidades, loucuras, suicídio e pelo ineditismo ao lidar com a questão irônica em seus textos, em que, na nossa opinião, reside a sua maior marca, já que é latente em seus textos uma contestação a uma forma literária e, ao mesmo tempo, o uso de um palavreado rebuscado tido como canônico.

De forma pontual, é o que podemos encontrar em "Os Canibais", texto extremamente pontuado por ironias que, ainda nos dias de hoje, pode prender a atenção do leitor, já que contêm, em sua essência, aspectos de modernidade.

\section{O narrador antropofágico, o banquete maldito.}

É salutar apontarmos que, quando Álvaro do Carvalhal escreve "Os Canibais", havia no meio literário a convivência entre uma corrente ultrarromântica (já exaurida) e um realismo (que dava seus primeiros passos). Esse aparte se faz importante, pois ambas correntes estéticas são parodiadas por Carvalhal. Ele constrói uma crítica ao romantismo: "Avultava contudo ali uma vista dessossegada e inquieta, que, sobretudo, feria alguns observadores, que nem curavam de ocultar o frenesi, que os assoberbava. Histórias do coração por certo" (CARVALHAL, 2004, p. 219) [grifo nosso], mas utiliza, grandemente, aspectos realistas em sua obra. Lemos, segundo alguns críticos, o seguinte acerca da obra de Carvalhal:

“[...] (porque o seu estilo também é uma criação) mas adentro de modelos clássicos ou arcádicos emparceirando com sugestões ultraromânticas. Já tudo isso é estranho mormente num moço. [...] O que já não é tão normal ou, se quiserem, vulgar, é que Álvaro do Carvalhal exagera. Exagera no estilo, como exagera em tudo. Ultrapassa as medidas, vai além da meta... se as suas histórias já são monstruosas, a linguagem em que estão contadas ainda sublinha essa monstruosidade: é 
uma linguagem repuxada ao máximo, visando de tal modo ao efeito que pode produzir, chega a produzir efeito contrário: cair no grotesco, no burlesco, no ridículo. (MIRAGLIA, 2004, p.301) [grifo nosso]

É exatamente esse 'ultrapassar' de fronteiras que encontramos em “Os Canibais": o exagero está a serviço de Carvalhal, como intensificador da sua proposta. De tal forma, encontraremos uma mescla de elementos postos que, é impossível, a um leitor realmente atento, não perceber traços de um ou outro 'lugar', fazendo da própria escrita, para além do enredo, um objeto fantástico, ao passo que, assim como é próprio do gênero, produz surpresa a cada linha lida.

O narrador de "Os Canibais" é um cicerone. Assim, 'procura' deixar seu leitor bem à vontade no percurso que se dispõe a mostrar. Inúmeros são os momentos cômicos, visto que o enredo se encaminha para algo assustador a nos ser revelado no final. Porém, mesmo com o uso 'excessivo' de traços cômicos, o enredo 'assombrado' se mantém, já que os momentos de riso, algumas vezes, se mesclam a uma tensão crescente. Para exemplificar:

- Mas não. Conservo a última esperança. Se a perder, já te mostrei o veneno que escolhi. Deixar-te-ei viúva e virgem, e rica, muito rica. Das multidões, que, famintas, se hão-de atropelar à entrada do teu palácio, podes eleger um esposo que te mereça, que te dê na terra venturas do céu. Não chores, anjo... (CARVALHAL, 2004, p.249)

Um dramalhão! A cena a qual este trecho está ligado é uma conversa entre Margarida e o Visconde de Aveleda, na noite de núpcias do casal, quando ele pretende revelar o seu grande segredo para a sua amada. Ora, em um momento de grande comoção, como é a revelação de um grande segredo, encontramos claramente traços de humor, como que postos para retirar a tensão, a qual o leitor, se bem atento, está intimamente ligado.

Apontamos anteriormente para a questão da paródia, ou de certa forma, crítica a certas escolas literárias. Logo ao início do relato, o narrador nos coloca a par do ambiente que passaremos a observar. Antes, contudo, ele faz uma grande defesa de sua história, trazendo-a para o campo da verdade, já que, em suas palavras: “[...] a inventar, no que iria grande perigo de volver costas à verdade" (CARVALHAL, 2004, p.217) [grifo nosso]. Sua narrativa, do ambiente no qual o enredo se desenvolve, é tão minimamente detalhada que é impossível não imaginar, a cada frase, o que ele descreve:

Quem não sabe o que é um baile? E todavia sinto-me tentado a descrevê-lo, sem desconhecer que nisso irá falta de modéstia, e trabalho verdadeiramente ocioso. Mil poetas, no exagero de aprimorados versos, têm sabido pintá-lo, sem omissão de algum dos matizes, que o 
abrilhantam. Melhor será, portanto, que o leitor veja a descrição do meu baile em qualquer poema artisticamente fantasioso, porque nisto de descrições não há sair do mesmo terreno. Senão, aqui lhe dou os traços de um aligeirado esboço! Flores das mais odorantes em gigantescos jarrões de esmaltada porcelana; a arte a revelar-se por toda a parte, na moldura dos espelhos, nos painéis, nos tectos dourados; emanações balsâmicas a exalarem-se por esses recintos encantados; ao longe uma música voluptuosa, não se de que maestro inspirado; e, sobressaindo a tudo, pares animados de muita vida e muito amor, abandonando-se à efervescência das danças, correndo agora numa iriada mistura de cores, para ligeiros se separarem logo debaixo dos olhos curiosos dos que se contentam em ver, esteiados com certo estudado ao mármore das colunatas, ou recostados nas voluptuosas otomanas. O sol majestoso dum formoso dia de verão não se projecta mais radiante sobre as asas e sobre as pétalas, ricamente variegadas de mil borboletas e de mil flores, do que aqueles centenares de sóis artificais, dardejados dos cristais reluzentes, sobre as vestes sumptuosas, que as damas arrastavam pelos aveludados tapetes. (CARVALHAL, 2004, p.218-219) [grifo nosso]

Como acabamos de perceber, uma longa descrição, que poderia parecer desnecessária é paradoxalmente necessária ao cabo que, como prenunciado pelo narrador ao começo do conto, estamos diante de um fato verdadeiro, real. Logo, para o narrador, o baile não pode simplesmente ficar na fantasia, ou mesmo na esperança de que o leitor já tenha participado de algum. Há a necessidade de descrição, a realidade deve ser descrita incansavelmente, ou, tudo (segundo a perspectiva do nosso narrador), seria apenas uma história inventada.

Essas interrupções do narrador são partes necessárias na construção do fantástico que envolve o conto.

$\mathrm{Na}$ metade do texto, na parte VII, encontraremos outra vOz posta na narrativa. Contudo, essa voz não se apresenta, sendo por isso, então, difícil compreender sua origem - fazendo com que surjam especulações diversas: será o próprio narrador se fazendo passar por um crítico ou será que estamos diante de uma crítica provinda de um leitor sério? O narrador, ao cabo desta 'intromissão', se mostra um tanto indignado (sempre em tom irônico), e diz que tentará, para evitar futuras críticas, se esmerar para parecer ser o mais correto e natural possível - já que a mesma achincalhava a narrativa, encontrando nela pontos de fraqueza e, até mesmo, desconsiderando o conto como sendo, de fato, um conto (nos moldes produzidos por Poe ou Hoffmann). Vale aqui ressaltarmos que essa 'crítica' retrata o conto do começo ao final, sendo, portanto, uma crítica posterior à publicação completa de "A Estátua Viva”. Fica, assim, a dúvida: Álvaro do Carvalhal inseriu essa 
crítica quando estava se preparando para a publicação de seus contos ou J. Simões, como amigo íntimo, fez um adendo ao texto original? De toda forma, nenhuma resposta a essa dúvida retiraria a ironia do narrador, em fazer troça, até mesmo, do seu próprio infortúnio.

Voltando à questão do fantástico, pode-se dizer que a história que este narrador nos conta trata dos amores entre a romântica Margarida, "[...] uma das mulheres fatais, que atraem irresistivelmente." (CARVAHAL, 2004, p.219) e o misterioso Visconde de Aveleda. Ao sermos apresentados ao Visconde, já é possível vislumbrar toda a aura de desconhecimento que o circundava. Ninguém sabia ao certo de onde vinha e sua presença causava, entre homens e mulheres (principalmente), grande alvoroço. Sua melancolia e solidão encantam Margarida.

Porém, o coração de Margarida era vislumbrado por outro, Dom João. Uma exemplar caricatura do romântico. Eis um exemplo:

- Perdão, minha senhora, havia ele exclamado numa intonação fatal, perdão por ousar importuná-la. Não pude resistir à tentação de vir eu mesmo lavrar o diploma da minha infâmia, declarando-lhe que assisti, escondido, a tudo o que aqui se passou; e só para me deliciar agora na sua vergonha. O seu amante, senhora D. Margarida...

- Sr. D. João!...

- Descanse. Sou muito generoso para sacudir injúrias sobre um rival ausente. (...) (CARVALHAL, 2004, p.233) [grifo nosso]

Enfim, a intriga se encaminha para o final contendo, claro, muitos arroubos sentimentalistas, falas extravagantes e certos lances folhetinescos. No decorrer da história, vemos que D. João, inconformado com o casamento entre Margarida e o Visconde, espera pelo seu momento de vingança e que, Margarida, já casada, descobre por boca (e outras partes) do Visconde o seu segredo: ele era uma estátua viva. A construção da monstruosidade do Visconde de Aveleda lembra, em muito, a criação de Hoffmann em $O$ homem de areia.

Temos aqui alguns trechos:

- Foges-me, Margarida! Diz ele com dolorido acento. Amarguras-te de me ver a teu lado! Devia ser assim. Como eu te quero, não o sabes tu. Não sabes como o moribundo ama o último dia da existência que lhe foge.

$[\cdots]$

- Henrique, Henrique! Sinto que se dá entre nós alguma coisa de muito extraordinário. Perde-se-me a cabeça em mil estranhas conjecturas. Encontro-te na imobilidade do cadáver. Diz-me quem és, quem tu és, Henrique, que eu não sei conhecer-te... 
- Nem queiras. Basta saber que sou uma pobre alma, em busca dum corpo, que me abrigue; um coração ardente num peito gelado como a pedra duma vala funérea. [...]

$[\ldots]$

- Horroroso! prosseguiu em tom de expansiva ternura. Vou ser franco, é tempo. Vem, Margarida, minha esposa, vem para o pé de mim. Revestete de toda a tua coragem e escuta.

$[\ldots]$

- Mas quem és, quem serás tu?

- Vem pergunta-lo ao contacto do meu corpo inanimado e frio, como o de um defunto. Receias?

- Oh Henrique!

- Vem.

- Desfaleço. Não posso mais. Tenho medo. Se ao menos fosse isto um sonho!

- Adivinhaste. Isto é um sonho. Podes voltar para casa de teu pai. Eu não sou um homem.

- Pois que és, desgraçado?

- Uma estátua. (CARVALHAL, 2004, p.248,250-251)

Após a revelação macabra, temos o clímax do horror:

Fez um movimento. Ressoaram estalos como de molas. Horror! Sobre a poltrona caiu um corpo mutilado, disforme, monstruoso. Pernas, braços, os próprios dentes do visconde, brancos como formosos fios de pérolas, tombaram sobre os felpudos tapetes da Turquia, e perderam-se nas dobras de seu robe de chambre, que naturalmente se lhe desprendeu dos ombros.

O infeliz era um fenómeno, um aborto estupendo, que, em nossos dias valeria muito dinheiro a quem quisesse especular. Era ele poeta demais para isso.

$[\ldots]$

Margarida sentiu-se como petrificada. Mas, de repente, fulgurou-lhe a loucura nos olhos. Comprimiu com violência o coração, e, veloz como o pensamento, desapareceu por uma janela, desprendendo um grito agudo, dolorido, que se perdeu à distância, ao mesmo tempo que, por outra janela, se precipitava no aposento um homem com uma pistola em cada mão. Era D. João.

Por seu lado o visconde sopesara a queda de suas sonhadas aspirações. Borbulharam-lhe duas lágrimas dos olhos embaciados, que, desvairado, dirigira para o bufete em que tinha depositado o veneno, última esperança. Impotente porém para o aproximar dos lábios, não hesitou. Numa contorção de agonia extrema atirou-se ao pavimento e rolou sobre as brasas vivas do fogão. Cingiu-o bem depressa uma azulada, ténue, mas crescente labareda, e nem um gemido soltou. (CARVALHAL, 2004, p.252)

Para fechar esse trágico triângulo temos, ainda, o suicídio de D. João. Se lermos com atenção o conto, perceberemos desde o início da narrativa apontamentos do narrador que já nos antecipavam o sobrenatural. Encontraremos passagens como: "Julgara ver a 
estátua irónica do comendador" (CARVALHAL, 2004, p.221) ou "Pouco se the dava ao visconde do efeito que produzia. Não se erguera ainda da cadeira em que se havia deixado cair, e, afora algumas palavras delicadas, ou gestos a que se obrigava a cortesia, di-lo-iam insensível estátua" (CARVALHAL. 2004, p.223) [grifo nosso], que claramente desvelam o mistério, sem, contudo, explicá-lo - e, mesmo após o fim da leitura, continuamos a nos questionar: por que o corpo de uma estátua? A essa pergunta não encontramos respostas, nem na narrativa, tão bem ilustrada por nosso irônico narrador, nem nas análises que porventura possamos fazer. Esse questionamento, ausente de uma resposta satisfatória, talvez reflita o que o teorizador de cinema francês Christian Metz diz:
A obra verossímil tenta persuadir-se, persuadir o público, de que as convenções que a levam a restringir os possíveis não são leis do discurso ou regras da escrita - não são, de modo algum, convenções - e que o seu efeito, constatável no conteúdo da obra, é na realidade o efeito da natureza das coisas e resulta dos caracteres intrínsecos do assunto representado. A obra verossímil quer-se, e quer que a considerem, diretamente traduzível em termos de realidade. É então que o verossímil encontra o seu pleno emprego: trata-se de fingir a verdade. (METZ, 1968, p.30-31) [grifo nosso]

Desde o início, a preocupação do narrador é trabalhar com a verdade. Ao criar um monstro, como o Visconde de Aveleda, ele também constituiu leis e regras nesse mundo que ele habita. A dúvida pode, então, ser a resposta mais certa para a nossa pergunta.

Porém, se por um lado não encontramos respostas aos nossos questionamentos, por outro temos elementos na narrativa que marcadamente encaminham a história para o seu ápice soturno. O que pode nos colocar diante, portanto, de uma 'literatura frenética' que se baseia num esbanjar de fortes sensações, com grande exploração da melancolia e das paixões violentas. Além, claro, da presença do macabro e do exagero.

Há de se perceber que, por mais livre que seja a escrita fantástica, ela é fruto de uma considerável contenção de recursos narrativos. Monstros, então, não podem existir somente no caos, é necessária certa ordem! O irônico narrador de "Os Canibais" nos ilude uma vez que no caminho da leitura ora nos traz para dentro do texto, como expectadores da cena relatada, ora nos retira e nos coloca como meros leitores que somos. Ao mesmo tempo em que nos ilude com o fantástico, nos faz refletir sobre a sua criação. Obra, essa, de gênio! 


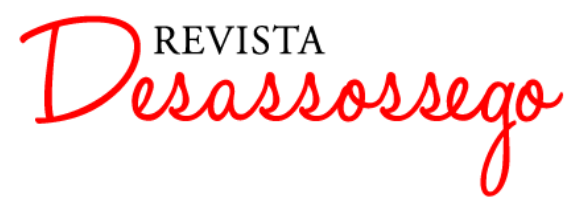

Ao nos encaminharmos para as palavras finais, restam algumas dúvidas: onde podemos enquadrar toda a questão da antropofagia e onde está o banquete maldito, anunciado no subtítulo desta sessão?

Antropofagia nos remete ao movimento brasileiro do início do século XX, de iniciativa do poeta Oswald de Andrade, que tinha como pretensão o 'devorar' (daí o caráter metafórico da palavra 'antropofágico') de culturas externas e internas, não negando nada a que se tivesse acesso. Mesmo irônico, nosso narrador antropofágico se permite buscar, ainda que para criticar, formas e elementos que estejam além de seu estilo. Ruminando, lentamente, tudo que possa de forma eficiente, agregar. Agindo como em muitas tribos, ao redor do globo, onde se comem pedaços de 'inimigos' ou de 'pessoas importantes' a fim de agregar, em si, as melhores características.

O banquete maldito é outra grande ironia de nosso exímio narrador, como podemos ver:

- Não. A carne assada. Meu genro, cada vez estou mais convencido, é um homem de inqualificáveis caprichos, duma rara excentricidade. Saiu, ninguém sabe quando, nem para onde; ao menos não há criado que o diga; saiu com a noiva e deixou nas brasas do fogão um imenso pedaço de carne, quase reduzido a cinzas, com exceção da parte superior, que repele o mais sorumbático fastio.

- E então?...

- Então aquilo deve ser alguma preciosidade da inventiva culinária do visconde. E para seu castigo lembrei-me de the pregar uma pirraça, por cima, há-de fazê-lo rir. Vinde almoçar comigo.

$[\ldots]$

Pouco depois entrava o velho folgazão com os dois filhos na câmara dos desposados, munido ele próprio dos apetrechos indispensáveis para o notável festim.

O sabor da carne não correspondia à aparência. Era excessivamente insulsa, viscosa e adocicada. [...]

[...] Supunha ter tocado com a faca alguma coisa, como uma caveira humana transformada pela acção do fogo.

- Meu pai! Exclamou ele de repente com voz espavorida, aqui há um terrível segredo, um segredo muito espantoso. [...]

$[\ldots]$

- Mas o visconde? Que fazia no entretanto o visconde? pergunta o atribulado velho.

D. João abriu pela última vez as pálpebras, e desprendeu a existência nestas últimas palavras:

- Procurem-no nas chamas do...

- Nas chamas?...Ah!

$[\cdots]$ 
- Comemo-lo, respondem os dois com voz de dentro.

- Comemo-lo, repete o venerando ancião. (CARVALHAL, 2004, p.257-258,264-265) [grifo nosso]

Movidos pela ganância e pela gula, os irmãos e o pai de Margarida acabam por comer o resto que sobrara do Visconde de Aveleda. A construção dessa cena, como as outras, possui um exagero extremado, misturado a uma comicidade.

Após o desespero, e dando sinais de que o suicídio seria uma solução para momento, os três se sentem aliviados ao lembrarem que eram os únicos herdeiros de toda fortuna do finado (e devorado) Visconde. Deixando, assim, para trás toda culpa e se banqueteando, novamente. Podemos, aqui, perceber uma crítica de Álvaro do Carvalhal à sociedade burguesa com suas falsas aparências, sua imoralidade e sua falta de escrúpulos, já que a riqueza é o alívio para o ato horrendo que anteriormente cometeram.

Ora, o rito ‘antropofágico’ encaminha o leitor diretamente para a aversão do que havia sido feito, no entanto, a sua desconstrução através da ação marcadamente capitalista por parte dos glutões encaminha para que se crie, internamente, uma barreira com relação ao uso do fantástico, ou dos elementos que a ele estejam ligados. É como se presenciássemos, pela leitura, o devorar e o regurgitar da temática: não há apreensão de qualidades positivas do que fora engolido, posto que aquilo não se interliga, verdadeiramente, à nossa essência. De toda forma, o fantástico deixa suas marcas, como a nos lembrar de que, num baile qualquer, sempre é possível encontrarmos uma estátua viva ou a ganância disfarçada de arrependimento.

\section{REFERÊNCIAS BIBLIOGRÁFICAS}

BRUNO, Sampaio. A geração nova (os novelistas). Porto: Lello \& Irmão, 1984.

CARVALHAL, Álvaro do. Contos. Lisboa: Assírio \& Alvim, 2004.

CORDEIRO, Luciano. Livro de crítica: arte e literattura portugueza nos dias d'hoje, 1868 - 1869. Porto: Typographia Lusitana, 1869. p. 289-290

MACHADO, Álvaro Manuel. Les romantismes au Portugal, modèles étrangers et orientations nationales. Paris: Fondation Calouste Gulbenkian, 1986. 
MIRAgLIA, Gianluca. Álvaro do Carvalhal. In: CARVALHAL, Álvaro do. Contos. Lisboa: Assírio \& Alvim, 2004. p.269-326.

METZ, Christian. Le dire et le dit au cinéma. Communications, Paris: SEUIL , n.11, p.2233, 1968.

OLIVEIRA, Maria do Nascimento. O fantástico nos contos de Álvaro do Carvalhal. Lisboa: Instituto de Cultura e Língua Portuguesa, 1992.

Artigo recebido em 26 de abril de 2014

Artigo aceito em 24 de junho de 2014 